\title{
A Pragma-Dialectical Study on Chinese Foreign Ministry Spokesperson Geng Shuang's Remarks on Japan's New Defense White Paper
}

\author{
Zhang Tong, Tian Jianguo, and Wang Fangyuan
}

\begin{abstract}
In Chinese Foreign Ministry Spokesperson's Remarks, the spokesperson always justifies standpoints or refutes the claims. From this perspective, the spokesperson's remark is a kind of argumentative discourse. Therefore, this paper studies Foreign Ministry Spokesperson Geng Shuang's Remarks on Japan's New Defense White Paper from the perspective of Pragma-dialectics and hopes to be helpful for researches on political texts. In strategic maneuvering, for potential topic, the spokesperson Geng Shuang chooses legality and peace as the topics that are commonly accepted and so is helpful for three argumentations, which indicates choosing the topics which accord with most people's values can be useful in argumentation. For audience demand, the argumentation made by the spokesperson meets the demands of three groups of audience, which indicates the arguer should meet the demands of different groups of audience. And for presentation device, the spokesperson uses contrast to make his argumentation more convincing. In the analysis of Ten Commandments, the selected Foreign Ministry spokesperson's remarks obey three commandments which are Relevance rule, Argument scheme rule and Validity rule.
\end{abstract}

Index Terms-Foreign ministry spokesperson's remark, pragma-dialectics, political texts.

\section{INTRODUCTION}

Chinese Foreign Ministry Spokesperson's Remark is one of the most critical channels through which the Chinese government releases information on diplomatic activity, clarifies China's domestic and foreign policy, and explains China's position on major global issues to the international public. [1] In addition, it is a crucial information source from which foreign media reports on China's domestic and foreign affairs. When facing various questions posed by foreign journalists, the spokesperson should not only stick to the Chinese governmental position but also rationalize it to sustain the image of the Chinese government. [2] Chinese Foreign Ministry Spokesperson's Remark can be regarded as a kind of argumentative discourse. So this paper studies Chinese Foreign Ministry Spokesperson's Remark from the perspective of Pragma-dialectics.

\section{THEORETICAL FRAMEWORK}

\section{A. Definition of Argumentation in Pragma-Dialectics}

In Pragma-dialectics, argumentation is defined as "a

Manuscript received July 24, 2018; revised September 17, 2018.

The authors are with the Northwestern Polytechnical University, China (e-mail: 13201761015@163.com). communicative and interactional (speech) act complex aimed at resolving a difference of opinion before a reasonable judge by advancing a constellation of reasons the arguer can be held accountable for as justifying the acceptability of the standpoint(s) at issue". [3] This concept of argumentation could be understood from two perspectives: from the perspective of pragmatics, each argumentative move is treated as a speech act which aims to resolve the difference of opinion; from the perspective of dialectics, argumentation is regarded as a part of critical discussion.

\section{B. Argumentation as a Part of Critical Discussion}

From the late 1970s to the 1990s, Dutch scholars Frans Van Eemeren and Rob Grootendorst, by combining dialectics and pragmatics with other disciplines (e.g., discourse analysis, communication, and logics), created the new discipline of Pragma-Dialectics, which has a considerable international influence on the development of argumentative discourse analysis. In Pragma-Dialectics, "argumentation is defined as a communicative and interactional (speech) act complex aimed at resolving a difference of opinion before a reasonable judge by advancing a constellation of reasons the arguer can be held accountable for as justifying the acceptability of the standpoint(s) at issue". In Pragma-Dialectics, a critical assumption is that each party in the argumentation is a rational person who can engage in discussions in a rational manner. To be able to manage any differences of opinion by parties in a rational manner, there needs to be an argumentative discussion, which is different from the informative discussion that serves primarily to convey information. Since informative and argumentative elements are often combined in our daily-life discussion, argumentative discussion is a part of a critical discussion involving both argumentative and informative discussions. "Ideally, an argumentative discussion is a critical discussion aimed at resolving a difference of opinion". [4] As mentioned with the theoretical definition of argumentation in the introduction, argumentation has four essential characteristics: First, rather than being only a structural entity, argumentation is a communicative act complex, which is realized by executing functional verbal communicative actions. This characteristic leads to the adoption of the metatheoretical principle of "functionalization." Second, rather than being only a monologue, argumentation is an interactional act complex aimed at producing certain responses from the person to whom it is addressed. This characteristic leads to the adoption of the metatheoretical principle of "socialization." Third, instead of being only a free-flowing expressive act, 
argumentation involves positing propositions in a manner that creates commitments to which one can be held accountable. This characteristic leads to the adoption of the metatheoretical principle of "externalization." Finally, rather than only speculating on instincts and emotional states, argumentation involves, by its constructive nature, an appeal to reasonableness that derives its force from the notion of common critical standards. This characteristic leads to the adoption of the metatheoretical principle of "dialectification". Differing from studies on argumentative discourse from the logical and rhetorical approaches, argumentation research from the pragma-dialectical perspective should adhere to these four metatheoretical principles: functionalization, externalization, socialization, and dialectification. Functionalization means that every language activity is considered a purposive speech act. Externalization means that argumentation focuses on public commitments undertaken by the participants of the language activities. Socialization means that argumentation is regarded as an explicit or implicit dialogue between more than two participants, ensuring that the interaction takes place through the language activity. Finally, dialectification means that the language activity is regarded as a critical discussion for resolving differences of opinion according to the critical norms of reasonableness. [5] These four principles are also the introductory points of the analysis and evaluation of argumentative discourse.

\section{Ideal Model of a Critical Discussion}

In Pragma-Dialectics, a critical discussion aimed at resolving differences of opinion often proceeds through four stages: confrontation, the opening, argumentation, and the conclusion. The four stages are analytically distinguished as in the following model:

" 1 . In the confrontation stage the parties establish that they have a difference of opinion.

2. In the opening stage the parties decide to try to resolve the difference of opinion. They assign the roles of protagonist and antagonist. They also agree on the rules for the discussion and on the starting points.

3. In the argumentation stage the protagonist defends his or her standpoint against the sometimes persistent criticism of the antagonist by putting forward arguments to counter the antagonist's objections or to remove the antagonist's doubts.

4. In the concluding stage the parties assess the extent to which the difference of opinion has been resolved and in whose favor."

The four stages comprise an ideal model of a critical discussion, but in the real world, argumentative discourse does not necessarily undergo these four stages. For example, their sequences may be crossed or repeated, one stage may not be obvious, and even with differences of opinion, the views of each party and other critical factors may appear missing. To analyze and evaluate the argumentative discourse easily necessitates reconstructing the argumentative discourse according to the four stages of the ideal model for a critical discussion. The argumentative discourse can be reconstructed in one of four ways: deletion, addition, substitution, and permutation. By reconstructing the four stages, an analytical overview can be devised, one in which all aspects of an argumentative discussion that are relevant to a critical evaluation are addressed. The analytical overview has six critical aspects: a difference of opinion, standpoints, starting points, the argumentation structure, argument scheme, and the argumentation result, which collectively considerably facilitate further analysis and the evaluation of argumentative discourse. [6]

\section{Strategic Maneuvering between Reasonableness and Effectiveness}

The purpose of argumentation is to eliminate a difference of opinion in a reasonable manner. In the real world, people want to maintain reasonableness, but they are also hoping to convince others effectively in every action involved in all the stages of argumentative discourse. To overcome the "argumentative dilemma" of having to combine effectiveness with reasonableness, Van Eemeren and Peter Houtlosser introduced the concept of strategic maneuvering. "Strategic maneuvering refers to the continual efforts made in all moves that are carried out in argumentative discourse to keep the balance between reasonableness and effectiveness". Each strategic maneuvering in a different move has its respective characteristics and aim. People strategically maneuver from three aspects: "potential topic," "audience demand," and "presentation device."

\section{E. Ten Commandments for a Reasonable Critical Discussion}

After proposing the ideal model of a critical discussion, for the sake of making sure that the ideal model could be implemented in a more disciplined way, Eemeren further proposed that the discussion operations and the rules the speech act must follow, which are known as the Ten Commandments for a Reasonable Critical Discussion. According to their idea, the violation of the rules will lead to fallacies. The content of "ten commandments" is as follows:

1. Freedom rule

Parties must not prevent each other from advancing standpoint or casting doubt on standpoints.

2. Burden-of-proof rule

A party who puts forward a standpoint is obliged to defend it if asked to do so.

3. Standpoint rule

A party's attack on a standpoint must relate to the standpoint that has indeed been advanced by the other party.

4. Relevance rule

A party may defend his or her standpoint only by advancing argumentation related to that standpoint.

5. Unexpressed premise rule

A party may not falsely present something as a premise that has been left unexpressed by the other party or deny a premise that he or she has left implicit.

\section{Starting point rule}

No party may falsely present a premise as an accepted starting point, or deny a premise representing an accepted starting point.

7. Argument scheme rule

A standpoint may not be regarded as conclusively defended if the defense does not take place by means of an appropriate argument scheme that is correctly applied.

8. Validity rule 
The reasoning in the argumentation must be logically valid or must be capable of being made valid by making explicit one or more unexpressed premises.

9. Closure rule

A failed defense of a standpoint must result in the protagonist retracting the standpoint, and a successful defense of a standpoint must result in the antagonist retracting his or her doubts.

\section{Usage rule}

Parties must not use any formulations that are insufficiently clear or confusingly ambiguous, and they must interpret the formulations of the other party as carefully and accurately as possible.

\section{ANALYSIS OF CHINESE FOREIGN MINISTRY SPOKESPERSON'S REMARKS}

\section{A. Reconstruction of the Argumentation}

In this part, the selected Chinese Foreign Ministry spokesperson's remarks will be reconstructed into the ideal model of a critical discussion.

\section{1) Confrontation stage}

In the confrontation stage, the two sides establish that they have a difference of opinion. Therefore, in this part, this paper tries to find out what the difference of opinion is and what the opinions of both sides are. The question put forward by the journalist is to ask for spokesperson's reply to Japanese government's accusations on Chinese defense policies and military activities. In the first paragraph of spokesperson's answer to this question, the spokesperson uses "groundless accusations" to describe Japanese government's accusations and says "China is strongly dissatisfied with and firmly opposed to that". Then, in the second paragraph, the spokesperson uses several facts ("It is our inherent rights to patrol and enforce law in territorial waters off Diaoyu Dao", "China is exercising the legitimate rights that a sovereign state is entitled to under international law" and "the current situation in the South China Sea has been stabilized and cooled down") to prove Japanese government's accusations are groundless. These indicate that the spokesperson has the opinion that Chinese defense policies and military activities are proper. Meanwhile, Japanese government's accusations means it thinks Chinese defense policies and military activities are threatening. Therefore, the difference of opinion is whether Chinese defense policies and military activities are proper or not.

\section{2) Opening stage}

In the opening stage the both sides decide to try to resolve the difference of opinion. They assign the roles of protagonist and antagonist. They also agree on the rules for the discussion and on the starting points. Therefore, in this part, this paper confirms the protagonist and antagonist and the starting points.

In the argumentation, the both sides have to uses evidence to support themselves to eliminate the other side's doubts and opposition. In the press conferences held by China's Ministry of Foreign Affairs, the spokesperson always plays the role of the protagonist. But because of different contexts, the antagonist varies. Putting the background information into consideration, we can get two potential antagonists: 1 . Japanese government; 2 . those countries, organizations and groups who doubt Chinese defense policies and military activities. As Japanese government has conflict of interest on this issue, Japanese government does not tend to accept the protagonist's argumentation. Therefore, the antagonists are the latter.

Then, the starting points are confirmed. Starting points are the facts agreed by both sides. In the press conferences held by China's Ministry of Foreign Affairs, the spokesperson cannot have discussion with the antagonists directly. Therefore, the spokesperson has to suppose the starting points be agreed by both sides. From the statement "It is our inherent rights to patrol and enforce law in territorial waters off Diaoyu Dao, on which Japan has no right to make irresponsible remarks" and "China is exercising the legitimate rights that a sovereign state is entitled to under international law", we can find that to argue Chinese defense policies and military activities are legal is a starting point. Then, from the statement which describes Chinese peaceful cooperation with ASEAN countries and "the current situation in the South China Sea has been stabilized and cooled down", and the statement "in recent years, Japan has been overhauling its military and security policies and attempting to justify its military buildup and amending of constitution by exaggerating security threats in the neighborhood, which has garnered wide attention from regional countries and the international community", we can find that to argue Chinese defense policies and military activities are peaceful is a starting point.

\section{3) Argumentation stage}

In the argumentation stage the protagonist defends his or her standpoint against the sometimes persistent criticism of the antagonist by putting forward arguments to counter the antagonist's objections or to remove the antagonist's doubts.

According to the opening stage, the standpoint of the spokesperson, the protagonist, is that Chinese defense policies and military activities are proper. To defend this standpoint, the spokesperson makes three argumentations.

Argumentation 1: Chinese defense policies and military activities are legal.

1.1a "It is our inherent rights to patrol and enforce law in territorial waters off Diaoyu Dao"

$1.1 \mathrm{~b}$ "It is beyond reproach for China to carry out normal activities in the air and on the sea pursuant to international law, domestic laws and regulations and defense development needs."

1.1c "In carrying out necessary and appropriate facility construction on parts of the islands and reefs of Nansha Islands, China is exercising the legitimate rights that a sovereign state is entitled to under international law."

In this argumentation, the spokesperson tries to defend the standpoint that Chinese defense policies and military activities are legal and rightful, and there are three supporting argumentation to help defend this standpoint. The argumentation 1.1a indicates the waters off Diaoyu Dao belong to Chinese territory and so Chinese military activities there are legal. The argumentation $1.1 \mathrm{~b}$ states Chinese normal activities in the air and on the sea conform to international laws and domestic laws. And the argumentation 1.1c indicates that Chinese facility construction on parts of the islands and 
reefs of Nansha Islands conforms to international laws. These three supporting argumentations help to prove Chinese defense policies and military activities are legal and rightful.

Argumentation 2: Chinese defense policies and military activities are peaceful

2.1 "With the concerted efforts of regional countries, the current situation in the South China Sea has been stabilized and cooled down."

2.1.1 "Meanwhile, China and ASEAN countries are focusing on stepping up cooperation, promoting comprehensive and effective implementation of the DOC and jointly working out regional rules."

2.1.2 "Various parties have fully affirmed the positive and sound momentum of the current situation in the South China Sea, and the foreign ministers of China and ASEAN countries have approved the framework of the COC and highly commended the hotline among senior officials of foreign ministries and other early harvests."

In this argumentation, the spokesperson states that the current situation in the South China Sea has been stabilized and cooled down. And to support this statement, the spokesperson present two facts related to Chinese efforts and achievements of making the situation of South China Sea peaceful and stable. Chinese actions which promote peaceful situation in South China Sea indicate indirectly that Chinese defense policies and military activities are peaceful rather than threatening.

Argumentation 3: Japanese defense policies and military activities do not tend to be peaceful.

3.1 "In recent years, Japan has been overhauling its military and security policies."

3.2 Japan has been "attempting to justify its military buildup and amending of constitution by exaggerating security threats in the neighborhood".

In this argumentation, the spokesperson uses two facts to shows Japanese government's behaviors causing security threats, which indicates that Japanese defense policies and military activities do not tend to be peaceful.

Therefore, in this argumentation stage, the spokesperson uses three argumentations to defend his standpoint. The argumentation 1 proves Chinese defense policies and military activities are legal and rightful. The argumentation 2 proves Chinese defense policies and military activities are peaceful. The argumentation 3 proves Japanese defense policies and military activities do not tend to be peaceful, which implies that Japanese government's accusations on Chinese defense policies and military activities are groundless because it is Japanese government that makes threats to world peace.

\section{4) Concluding stage}

In the concluding stage the parties assess the extent to which the difference of opinion has been resolved and in whose favor. As the antagonists are those countries, organizations and groups who doubt Chinese defense policies and military activities, the antagonists cannot communicate directly with the spokesperson on the press conferences held by China's Ministry of Foreign Affairs. Therefore, the extent to which the difference of opinion has been resolved and in whose favor are not sure.

\section{B. Analysis of Strategic Maneuvering}

Strategic maneuvering refers to the continual efforts made in all moves that are carried out in argumentative discourse to keep the balance between reasonableness and effectiveness". Each strategic maneuvering in a different move has its respective characteristics and aim. People strategically maneuver from three aspects: "potential topic," "audience demand," and "presentation device." Therefore, in this part, the strategic maneuvering used in the selected Chinese Foreign Ministry spokesperson's remarks will be analyzed from these three aspects.

1) Potential topic

Potential topic refers to the selection of topics in different moves. In the selected Chinese Foreign Ministry spokesperson's remarks, there are two starting points. One is to argue Chinese defense policies and military activities are legal, and the other is to argue Chinese defense policies and military activities are peaceful. The first starting point is used in argumentation 1 and the second starting point is used in argumentation 2. Therefore, we can find that the topic of argumentation 1 is legality and the topic of argumentation 2 is peace. Then, these two topics will be analyzed.

Legality: this topic is helpful for the arguer. First, international law refers to the body of rules generally recognized by civilized nations as governing their conduct towards each other and towards each other's subjects in international society. Every country is obligatory to obey international laws. Choosing legality as the topic can make the argumentation more forceful. Second, the majority of the countries in the world use legal system, and so the citizens and governments of these countries have the common value of obeying laws. Therefore, when the spokesperson uses the statement that Chinese defense policies and military activities confirm to international laws to defend his standpoint, the spokesperson can get more support from these citizens and governments. Because of the obligation of the countries obeying the international laws and the common value of obeying laws, the topic legality is helpful for the argumentation 1.

Peace: peace is the main topic of international society. To maintain world peace is the obligation of the members of international society. And the value of world peace is accepted by most citizens in the world. These two advantages make the argumentation 2 more convincing. Therefore, choosing this topic is beneficial to the arguer.

\section{2) Audience demand}

Audience demand means the argumentation meets the demand of audience. In this part, this paper will analyze how the argumentation meets the demand of audience.

First, the argumentation made by the spokesperson meets the demand of those audience who are concerned about Chinese defense policies and military activities. For example, the statements "In carrying out necessary and appropriate facility construction on parts of the islands and reefs of Nansha Islands" and "the current situation in the South China Sea has been stabilized and cooled down" meet the demand of those countries who are located near the region of South China Sea because those countries want to know Chinese explanations for its activities on this region. 
Second, in the selected Chinese Foreign Ministry spokesperson's remarks, the spokesperson states Chinese defense policies and military activities are legal and peaceful, which meets the demand of audience who accept the common value of legality and maintaining world peace.

Third, in the last paragraph of selected Chinese Foreign Ministry spokesperson's remarks, the spokesperson states Japanese government's behaviors causing threats to world peace, which meet the demand of those audience who know about Japanese government's inappropriate behaviors and so doubt Japanese government's accusations on Chinese defense policies and military activities.

\section{3) Presentation device}

Presentation device refers to the choices of linguistic forms like sentence patterns and rhetoric in different moves.

In the selected Chinese Foreign Ministry spokesperson's remarks, the spokesperson uses contrast as a presentation device. In argumentation 2, the spokesperson states "the current situation in the South China Sea has been stabilized and cooled down", and then states Chinese government's peaceful cooperation with the countries near the South China Sea, which describes a peaceful, friendly image of China. Meanwhile, in argumentation 3, the spokesperson states "In recent years, Japan has been overhauling its military and security policies and attempting to justify its military buildup and amending of constitution by exaggerating security threats in the neighborhood", which shows an aggressive and threatening image of Japan. Therefore, for the defense policies and military activities, there is a sharp contrast between China and Japan, and this contrast highlight that China is carrying out peaceful defense policies and military activities. By using this contrast, the argumentation 2 is more convincing.

\section{Ten Commandments for a Reasonable Critical Discussion}

After proposing the ideal model of a critical discussion, for the sake of making sure that the ideal model could be implemented in a more disciplined way, Eemeren further proposed that the discussion operations and the rules the speech act must follow, which are known as the Ten Commandments for a Reasonable Critical Discussion. These Ten Commandments include: 1. Freedom rule. 2. Burden-of-proof rule. 3. Standpoint rule. 4. Relevance rule. 5. Unexpressed premise rule. 6. Starting point rule. 7. Argument scheme rule. 8. Validity rule. 9. Closure rule. 10. Usage rule. Therefore, in this part, the selected Chinese Foreign Ministry spokesperson's remarks will analyzed according to these Ten Commandments.

In these Ten Commandments, some commandments require specific argumentations of both sides, but this paper studies the selected Chinese Foreign Ministry spokesperson's remarks which only present the argumentations of the spokesperson. Therefore, in this part, only commandment 4, commandment 7, commandment 8 , will be used to analyze the selected Chinese Foreign Ministry spokesperson's remarks.

\section{1) Commandment 4}

Commandment 4 is the Relevance rule.

Relevance rule: A party may defend his or her standpoint only by advancing argumentation related to that standpoint. In the selected Chinese Foreign Ministry spokesperson's remarks, the standpoint of the spokesperson is that Chinese defense policies and military activities are proper. To defend this standpoint, the spokesperson uses three argumentations. Argumentation 1 wants to prove Chinese defense policies and military activities are legal. Argumentation 2 wants to prove Chinese defense policies and military activities are peaceful. Argumentation 3 wants to prove that Japanese defense policies and military activities do not tend to be peaceful, which indicates Japanese government's accusations are groundless and so proves Chinese defense policies and military activities are proper. Therefore, these three argumentations are all related to the standpoint. So the relevance rule is obeyed.

\section{2) Commandment 7}

Commandment 7 is the Argument scheme rule.

Argument scheme rule: A standpoint may not be regarded as conclusively defended if the defense does not take place by means of an appropriate argument scheme that is correctly applied. Therefore, this rule asks the arguer to use appropriate argument scheme. Argument schemes present common patterns of linking premises, claims offered in support of a contention, and conclusions. And after analyzing the selected material, this paper finds that the spokesperson uses appropriate argument scheme. And this is an example:

In the selected material, there is an argumentation:

"In carrying out necessary and appropriate facility construction on parts of the islands and reefs of Nansha Islands, China is exercising the legitimate rights that a sovereign state is entitled to under international law."

And its argument scheme is:

Reason: [carrying out necessary and appropriate facility construction on parts of the islands and reefs of Nansha Islands] for [China] is true.

Meanwhile: [carrying out necessary and appropriate facility construction on a country's own territory] is the characteristic of [exercising the legitimate rights].

Conclusion: [exercising the legitimate rights] for [China] is true.

\section{3) Commandment 8}

Commandment 8 is the Validity rule

Validity rule: The reasoning in the argumentation must be logically valid or must be capable of being made valid by making explicit one or more unexpressed premises.

After analyzing the selected material, this paper finds that the reasoning in the 3 argumentations is logically valid. And let's take argumentation 1 as an example:

Argumentation 1: Chinese defense policies and military activities are legal.

1.1a "It is our inherent rights to patrol and enforce law in territorial waters off Diaoyu Dao"

$1.1 \mathrm{~b}$ "It is beyond reproach for China to carry out normal activities in the air and on the sea pursuant to international law, domestic laws and regulations and defense development needs."

1.1c "In carrying out necessary and appropriate facility construction on parts of the islands and reefs of Nansha Islands, China is exercising the legitimate rights that a sovereign state is entitled to under international law."

In this argumentation, the 1.1a proves Chinese activities in 
territorial waters off Diaoyu Dao are legal. The $1.1 \mathrm{~b}$ proves Chinese normal activities in the air and on the sea pursuant to international law, domestic laws and regulations and defense development needs are legal. The $1.1 \mathrm{c}$ proves Chinese necessary and appropriate facility construction on parts of the islands and reefs of Nansha Islands is legal. So 1.1a, 1.1b and 1.1c all help to prove Chinese defense policies and military activities are legal, which is logically valid.

\section{CONCLUSION}

This paper studies Chinese Foreign Ministry Spokesperson Geng Shuang's Remarks on Japan's New Defense White Paper from the perspective of Pragma-dialectics. After reconstruction of the ideal model of a critical discussion, analysis of strategic maneuvering, and analysis of Ten Commandments for a reasonable critical discussion, conclusion is reached.

In strategic maneuvering, for potential topic, the spokesperson chooses legality and peace as the topics that are commonly accepted and so is helpful for three argumentations, which indicates choosing the topics which accord with most people's values can be useful in argumentation. For audience demand, the argumentation made by the spokesperson meets the demands of three groups of audience, which indicates the arguer should meet the demands of different groups of audience. And for presentation device, the spokesperson uses contrast to make his argumentation more convincing. In the analysis of Ten Commandments, the selected Chinese Foreign Ministry spokesperson's remarks obey three commandments which are Relevance rule, Argument scheme rule and Validity rule.

\section{ACKNOWLEDGMENT}

Chinese Foreign Ministry Spokesperson Geng Shuang's remarks on Japan's New Defense White Paper

"Journalist: The Japanese government approved a new defense white paper on August 8which once again laid accusations on China's defense policies and military activities What is your comment?

Geng Shuang: In disregard of facts and harping on the same string, Japan's new defense white paper once again made groundless accusations against China's normal defense and military activities, made irresponsible remarks on China's maritime activities and tried to stir up troubles on the South China Sea issue. China is strongly dissatisfied with and firmly opposed to that and has lodged serious representations with the Japanese side.

I would like to stress that the Chinese government is determined in safeguarding the nation's territorial sovereignty and maritime rights and interests. It is our inherent rights to patrol and enforce law in territorial waters off Diaoyu Dao, on which Japan has no right to make irresponsible remarks. It is beyond reproach for China to carry out normal activities in the air and on the sea pursuant to international law, domestic laws and regulations and defense development needs. In carrying out necessary and appropriate facility construction on parts of the islands and reefs of Nansha Islands, China is exercising the legitimate rights that a sovereign state is entitled to under international law. It has nothing to do with "militarization", still less will it pose any threat to regional security. With the concerted efforts of regional countries, the current situation in the South China Sea has been stabilized and cooled down. Meanwhile, China and ASEAN countries are focusing on stepping up cooperation, promoting comprehensive and effective implementation of the DOC and jointly working out regional rules. Various parties have fully affirmed the positive and sound momentum of the current situation in the South China Sea, and the foreign ministers of China and ASEAN countries have approved the framework of the COC and highly commended the hotline among senior officials of foreign ministries and other early harvests. We hope the Japanese side to respect the efforts by China and ASEAN countries to uphold peace and stability in the South China Sea, stop hyping up and intervening in the South China Sea issue and play a more constructive role in promoting regional peace and stability.

In recent years, Japan has been overhauling its military and security policies and attempting to justify its military buildup and amending of constitution by exaggerating security threats in the neighborhood, which has garnered wide attention from regional countries and the international community. We urge the Japanese side to learn from history, stick to the path of peaceful development, watch its words and actions in the military and security fields, and contribute to enhancing mutual political and security trust between China and Japan and maintaining regional peace and stability, instead of the opposite."

\section{REFERENCES}

[1] S. Yao, "The style of the spokesman language," Journal of Beihua University, 2010.

[2] Z. Yang, Spokesman: Theory and Practice, Beijing: Communication University of China Press, 2005, pp. 3-7.

[3] F. H. V. Eemeren, Strategies Maneuvering in Argumentative Discourse: Extending the Pragma-dialectical Theory of Argumentation, Amsterdam: John Benjamins Publishing Company, 2010, pp. 27-40.

[4] F. H. V. Eemeren, R. Grootendorst, and A. F. S. Henkemans, Argumentation: Analysis, Evaluation, Presentation, London Lawrence, 2002, pp. 24-25.

[5] F. H. V. Eemeren and R. Grootendorst, A Systematic Theory of Argumentation: The Pragma-Dialectical Approach, Cambridge: Cambridge University Press, 2004, pp. 52-55.

[6] P. Wu. "Strategies maneuvering: Pragma-dialectical rhetoric," Journal of Fujian Normal University, 2015.

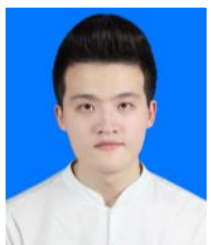

Zhang Tong was born on June 18th, 1995, Fuzhou city, Fujian province, China.

$\mathrm{He}$ has got his bachelor of arts in Northwestern Polytechnical University, Xi'an, China, In June, 2017. And he is pursuing the master's degree, majoring in applied linguistics in Northwestern Polytechnical University since September, 2017. His major Field of study is dialects.

He was a teaching assistant in the Middle School Attached to Northwestern Polytechnical University during March and April in 2017, and an assistant of Foreign Affairs Office of People's Government of Shaanxi Province. His current research interests include dialects.

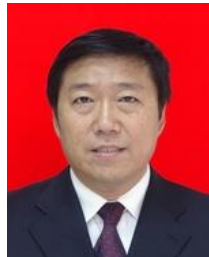

Tian Jianguo was born in June, 1959, in China. He has got his bachelor of English language and literature from Xi'an International Studies University, Xi'an, China, in July, 1983; the master of education from Emporia State University, Kansas State, the United States, in August, 1995.

His major field of study includes sociolinguistics and 
applied linguistics.

He was a teacher in Northwest Forestry College from 1983 to 1986. And from 1986 to 1992, he was the member of the faculty of Northwestern Polytechnical University; from 1992 to 1997, the visiting scholar in Emporia State University. From 1997 to today, he has been the professor of Northwestern Polytechnical University. From 2008 to 2013, he was the vice dean of College of Humanities and Law of Northwestern Polytechnical University. From 2013 to 2017, he was the vice dean and secretary of the Party committee of the School of Foreign Studies of Northwestern Polytechnical University. His previous publications includes: 1. Tian Jianguo, "Study on Vocabulary Learning Strategies from the Psycholinguistic Perspective Based On the Bilingual Mental Lexicon Structure", Foreign Language World, 2012(02):74-80. 2. Tian Jianguo, "Research on College English Writing on the Macro Discourse Level Based on Web Resourcers." Advances in Computer Science, Environment, Ecoinformatics and Education International Conference, CSEE 2011 Wuhan, China, August 2011. 3. Tian Jianguo, "Re-reflection on Cultura Context", Journal of Northwestern Polytechnical University (Social Sciences), 2012 (03):77-81+104. His current and previous research interests are sociolinguistics and applied linguistics.
Prof. Tian Jianguo is vice-chairman of the Association of Foreign Language Teaching in University Research of Shaanxi Province and Shaanxi Translators' Association. He is the member of Chinese Engineering Master's English Expert Group.

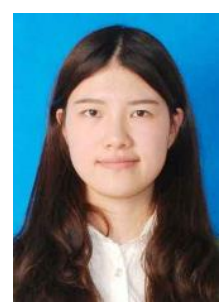

Wang Fangyuan was born in Hefei city, Anhui province in China on March 1st, 1995. She has got the bachelor's degree in Northwestern Polytechnical University, Xi'an city, China in June, 2017 with majored in English. She is pursuing for master's degree in Northwestern Polytechnical University since September, 2017, major in English literature now. Her major study field includes space narration, children literature, and immigrant literature.

She was a teaching assistant in the Middle Schoo Attached to Northwestern Polytechniacal University during March and April in 2017; TOEFL teaching assistant in New Oriental during July and August in 2017; Internship in the People's Government of Shaanxi Province in winter vacation in 2018 